\title{
MARCAS DAS EXPERIÊNCIAS SOCIAIS E INTERCULTURAIS DE ESTUDANTES \\ EM MOBILIDADE INTERNACIONAL: DOS LAÇOS DE AMIZADE AOS \\ "PERRENGUES”
}

TRACES OF SOCIAL AND INTERCULTURAL EXPERIENCES OF STUDENTS IN

INTERNATIONAL MOBILITY: FROM FRIENDSHIP TIES TO "HARDSHIP"

Recebido em: 26/09/2016 - Aprovado em: 07/12/2016

Avaliado pelo sistema double blind review

Editora Científica: Claudia Stadtlober

10.13058/raep.2017.v18n2.432

\section{CINTIA RODRIGUES DE OLIVEIRA MEDEIROS cintia@ufu.br}

ANTONIA DARLIANE DA SILVA ANDRADE

JANDUHY CAMILO PASSOS

UNIVERSIDADE FEDERAL DE UBERLÂNDIA

\section{RESUMO}

Das mudanças ocorridas quanto ao mercado de trabalho global, emerge a exigência por um perfil profissional com visão intercultural, entre outras características. Desde o início dos anos 2000, o governo brasileiro intensificou sua atuação nos programas de mobilidade estudantil de nível superior em âmbito internacional. No mesmo compasso, as universidades brasileiras, também, estimulam os estudantes à prática do intercâmbio, aderindo aos diversos programas de mobilidade nacional e internacional. Esta pesquisa teve como objetivo reunir e analisar experiências sociais e culturais de estudantes de administração da Universidade Federal de Uberlândia (UFU) relativas ao período vivido em mobilidade internacional. Para tanto, foram realizadas entrevistas semiestruturadas com oito estudantes do curso de Administração da UFU que participaram dos programas de Mobilidade Internacional nos últimos dois anos. Para a análise do corpus de pesquisa, foi utilizada a técnica de análise de conteúdo. Como resultado, foi identificado que as experiências sociais dos estudantes em mobilidade internacional são marcadas por laços de amizade, aventuras, conhecimento, fala negociada e "perrengues".

Palavras-chave: Mobilidade estudantil; Interculturalidade; Intercâmbio.

\section{ABSTRACT}

Among the changes in the global labor market is the demand for a professional profile that includes an intercultural vision, among other features. Since the early 2000s, the Brazilian government has intensified its presence in international mobility programs for higher education students. Accordingly, Brazilian universities also encourage students to have the experience of exchange, adhering to various national and international mobility programs. This research aims to gather and analyze social and cultural experiences of Business Administration students of the Federal University of Uberlândia during the period they lived in international mobility. Therefore, we conducted semi-structured interviews with eight Business Administration students that participated in International Mobility programs in the last two years. The technique of content analysis was used for analyzing the corpus. As a result, we identified that the social experiences of students in international mobility are marked by friendship ties, adventure, knowledge, negotiated speech and moments of "hardship".

Keywords: Student Mobility; Interculturality; Student Exchange. 


\section{INTRODUÇÃO}

Nesta pesquisa, abordamos a mobilidade estudantil, delimitando-nos às experiências sociais e culturais dos estudantes do curso de administração da UFU que participaram dos programas de mobilidade internacional. O tema abordado é relevante devido à sua atualidade e à importância que adquire no cenário internacional em face dos processos de globalização. Segundo Mazza (2011), o Brasil possui convênios, com cerca de 50 países, em desenvolvimento para receber estudantes em universidades públicas e privadas em todo o território nacional. Trata-se do "Programa de Estudantes-Convênio de Graduação (PEC-G), criado em 1920 e administrado, desde 1964, pelo Ministério das Relações Exteriores (MRE) e pelo Ministério da Educação (MEC). Em 1983, foi instituído o Programa de Estudantes-Convênio de Pós-Graduação (PEC-PG) em parceria com a CAPES/MEC e com o CNPq/Ministério da Ciência e Tecnologia" (MAZZA, 2011, p. 4). O Governo Federal brasileiro criou, em julho de 2011, seu principal programa de mobilidade estudantil, o Ciência sem Fronteiras (CsF), o Programa Brasileiro de Mobilidade Científica no qual áreas de estudo como tecnologia, engenharia, ciência e matemática foram apontadas como iniciativas estratégicas para o programa de bolsas de estudos. O intercâmbio passou a incentivar a preparação de jovens estudantes para uma economia mundialmente competitiva. O Programa Brasileiro de Mobilidade Científica foi planejado para situar o Brasil, de maneira positiva, em uma economia política competitiva (SPEARS, 2014).

No cenário atual, a mobilidade estudantil internacional nasceu como uma das alternativas para aprimorar o conhecimento de maneira diversificada. Segundo Guimarães (2013), a mobilidade internacional estudantil começou na Europa, no final do século XX, possibilitando uma evolução na conduta acadêmica, mas que exigiu a unificação de metodologias de ensino, por parte das universidades, para que isso pudesse acontecer.

Diante dessas considerações, a questão que orienta esta pesquisa é: Como se configuram as experiências sociais e culturais de estudantes de administração da FAGEN/UFU no período vivido em mobilidade inter- 
nacional? Para responder a essa questão, nesta pesquisa, foi estabelecido o objetivo de reunir e analisar experiências sociais e culturais de estudantes de administração da FAGEN/UFU quanto ao período vivido em mobilidade internacional. Esta pesquisa é de natureza qualitativa, sendo o seu corpus composto por entrevistas semiestruturadas com estudantes que participaram dos programas de mobilidade internacional.

Inicialmente, apresenta-se a revisão da literatura com os conceitos de mobilidade estudantil. Em seguida, descrevem-se os procedimentos metodológicos e expõe-se a discussão dos resultados encontrados. Por fim, explanam-se as considerações finais, incluindo as implicações da pesquisa, bem como se apontam sugestões para futuros estudos. 


\section{MOBILIDADE ESTUDANTIL INTERNACIONAL NO ENSINO SUPERIOR}

De acordo com Sebben (2007), o que hoje se conhece como mobilidade estudantil teve início antes do nascimento de Cristo, quando jovens se dirigiam para a Grécia com o objetivo de melhorar seus estudos e, posteriormente, poder voltar para seus países de origem e ajudá-los. Com o passar do tempo, esse tipo de viagem aumentou, igualmente com o desenvolvimento dos transportes e da comunicação, na era da Revolução Industrial.

Historicamente, as viagens de caráter educativo foram incentivadas a partir do século XVIII. Com o crescimento do capitalismo, no início do século XIX, e do momento que a Europa aumentou seu desenvolvimento apoiada na industrialização e na racionalização do trabalho, essas viagens que objetivavam o crescimento pessoal começaram a progredir e ficaram conhecidas como o Grand Tour, um programa (viagem de estudos) que tinha "valor de um diploma que lhes conferia significativo status social, embora - na realidade - a programação se fundamentasse em grandes passeios de excelente qualidade e repletos de atrativos prazerosos" (ANDRADE, 1998, p. 16).

De acordo com Guimarães (2013), a mobilidade internacional iniciou-se na Europa, no final do século XX, tendo proporcionado um desenvolvimento no comportamento acadêmico, para tanto, levando as universidades a unificarem suas metodologias de ensino para que isso pudesse ocorrer. O principal objetivo era qualificar os estudantes para o mercado de trabalho a fim de criar um padrão distinto dos demais continentes, mantendo a taxa de empregabilidade. Entretanto essa mobilidade beneficia os países menos desenvolvidos, que, dessa maneira, têm a possibilidade de enviar seus estudantes para estudar nas principais universidades europeias, desenvolvendo, em outros países, estudantes qualificados para trabalharem, em seu país de origem, com conhecimentos mais elaborados, desse modo, favorecendo o ensino aos que não tiveram tal oportunidade.

Com o término das Grandes Guerras, a mobilidade de docentes europeus para instituições dos EUA inaugurou a internacionalização da edu- 
cação como estratégia capaz de enriquecer o desenvolvimento. A partir daí, a quantidade de acadêmicos originários de países considerados subdesenvolvidos tem aumentado em direção aos grandes centros, onde a abertura para o exterior, o contato com outras culturas e o domínio de línguas estrangeiras tornaram-se aspectos importantes na formação de elites cosmopolitas (LIMA et al., 2009).

Portanto, a mobilidade acadêmica não é um acontecimento recente, na realidade, é fruto do desenvolvimento tecnológico ligado à globalização econômica e à ascensão do padrão de competitividade e concorrência entre as economias dos países (LIMA et al., 2009). O aprimoramento dos transportes e das tecnologias da informação, a internet, etc. contribuíram com a internacionalização de diversas instituições de ensino superior, tornando esse elemento uma figura visível da globalização.

Para Silva (2013, p. 50), a mobilidade internacional acadêmica é o principal elemento da "internacionalização do ensino superior. Tem significado político e econômico, além de consequências acadêmicas. As forças de mercado desempenham papel efetivo no aumento da demanda por um período de estudos no exterior". Para alguns autores, como Cabral, Silva e Saito (2011) e Stallivieri (2003), a internacionalização da educação é um dever das universidades. Oferecer aos seus estudantes a possibilidade de experiências internacionais para que se tornem mais qualificados para o mercado mundial faz parte das atribuições das universidades.

A mobilidade acadêmica é definida, por Silva (2013, p. 43), como "um período de estudo, ensino e ou pesquisa em um país que não seja o país de origem do estudante [...]. Este período é de duração limitada, e prevê-se que o estudante ou funcionário retorne ao seu país de origem após a conclusão do período designado". O autor inclui na sua definição a dimensão virtual, caracterizada por meio da educação a distância, como uma oportunidade de mobilidade acadêmica. Nessa definição, estão inseridas, também, duas categorias importantes da mesma mobilidade. Trata-se da mobilidade espontânea, pela qual todo o programa "depende exclusivamente da iniciativa do estudante ou de sua família, que financia sua viagem e estadia no exterior sem auxílio ou orientação institucional” 
(SILVA, 2013, p. 43). Quanto à mobilidade institucional, é aquela realizada por meio de programas de intercâmbios, em que ocorre a seleção dos estudantes, preparação para viver a experiência no exterior e, ainda, em alguns casos, há auxílio financeiro por meio de bolsas de estudos (MURPHY- LEJEUNE, 2008).

Nesse contexto, a palavra "intercultural" adquire importância cada vez maior nas instituições acadêmicas. Além das consequências oriundas da globalização econômica, houve um significativo crescimento na elaboração e transmissão de informações, que, por meio da internet e de diferentes meios de comunicações, eliminou limites geográficos, diminuiu o desconhecimento de umas nações sobre as outras e iniciou outras formas de sociabilidade. Todos esses elementos têm incentivado a necessidade do entendimento intercultural em diversos domínios da existência social. No meio acadêmico, os pesquisadores com maior reputação são aqueles que estudam no exterior, trabalham em conjunto com cientistas do mundo inteiro e têm publicações em âmbito internacional (FREITAS, 2009).

Para Contel e Lima (2007), nações com um sistema educacional experiente (disponível e relacionado com a época histórica) podem treinar seus habitantes para os desafios oriundos da modernidade. Porém está ocorrendo uma "privatização" do conhecimento que é fornecido nas universidades, pois os professores agem como especialistas fornecendo conhecimento fundamentado na ciência. Na visão de Beck (1999) e Ianni (1995), o número de indivíduos em mobilidade estudantil está em constante crescimento, visto que universidades e organizações inserem-se no mundo globalizado e concorrente internacionalmente. $\mathrm{O}$ mundo encontra-se em constante processo de integração social, política, cultural e econômica, encorajado, historicamente, pela necessidade de diminuição de preços dos meios de comunicação e transporte dos países no início do século XXI. É nesse sentido que as instituições acadêmicas têm firmado acordos em várias partes do mundo, dessa maneira, enviando seus estudantes para outros países a fim de que consigam aprimorar os conhecimentos obtidos na universidade de origem em um local diferente, por conseguinte, ganhando experiência na área de sua formação. 
Tomazzoni e Oliveira (2013) afirmam que o intercâmbio proporciona experiência para ambas as partes, tanto para o indivíduo que vive outra realidade quanto para quem recebe o intercambista. Ademais, o intercâmbio proporciona desenvolvimento pessoal em ambiente desconhecido. Uma das dificuldades é manter o próprio bem-estar no país estrangeiro. Com as diversas tipologias de mobilidade internacional, o estudante desenvolve habilidades que contribuem para o crescimento de sua carreira profissional, como colocam Lima et al. (2009). Para esses autores, a mobilidade internacional amplia o capital intelectual e contribui para o desenvolvimento de competências valorizadas pelo mercado de trabalho, conforme favorece o amadurecimento emocional dos jovens.

Outras habilidades apontadas por Barblan (2002) e Stallivieri (2009) estão relacionadas com o entendimento mais profundo no tocante aos conflitos do mundo, uma maior compreensão de outras culturas e comunicação intercultural. Já Murphy-Lejeune (2008) é objetivo ao concluir que a mobilidade acadêmica constitui um período de estudos no exterior, cuja duração pode ser de vários meses até um ano letivo, dessa forma, favorecendo o contato direto com idiomas e diferentes culturas. Ademais, ao viver uma experiência internacional, o estudante precisa adaptar-se a um país com outra cultura, outras realidades sociais e, possivelmente, iniciará uma revisão de valores.

Em convergência a essa linha de pensamento, Hill, Lynch e Dalley-Trim (2012) referem que a mobilidade acadêmica é uma forma de socialização secundária do indivíduo. Ao participar da mobilidade, o indivíduo consegue obter várias oportunidades e beneficiar-se dessa diversidade. Entretanto a mobilidade inclui oposição e conflito no que tange às diferenças, o que requer inúmeras habilidades para se adaptar e desenvolver novas competências. Por isso, a mobilidade acadêmica caracteriza-se por uma maneira de aprendizado que amplia os horizontes do indivíduo (HILL; LYNCH; DALLEY-TRIM, 2012).

Silva e Lima (2013) ressaltam que a mobilidade internacional estudantil é desejada por todos, pois proporciona aos países de destino a afirmação da superioridade acadêmica e os benefícios em termos políticos, 
econômicos e culturais. Porém Lima et al. (2009) destacam que o fluxo de estudantes internacionais é desigual à medida que desperta mais interesse entre os indivíduos originários dos países subdesenvolvidos (Coreia, Turquia, Marrocos, México, Brasil, etc.) do que dos países desenvolvidos - enquanto os EUA acolhem $26 \%$ dos estudantes internacionais, enviam $2 \%$. Já no Brasil, ainda há pouco interesse no assunto, talvez, devido à grandeza continental do país, à inexistência de demanda de compensações históricas frente aos colonizadores e à concordância social sobre o fato de ser uma nação e cultura influenciadas por diversos povos e culturas (FREITAS, 2009).

Para Spears (2014), a mobilidade estudantil no Brasil, chamada de intercâmbio, não é um acontecimento novo. Segundo Luna e Sehnem (2013), a mobilidade estudantil aprimorou-se e expandiu-se para programas de maior variedade e extensão em número de estudantes, professores e instituições. Os referidos autores citam como exemplo de programas de mobilidade estudantil Erasmus, na Europa, e Ciência sem Fronteiras, no Brasil. Silva (2013) acha importante destacar que o Brasil contribui para ampliar o crescimento de mobilidade acadêmica, pois, "segundo o relatório Education at a Glance - 2012 divulgado pela Organização para a Cooperação e Desenvolvimento Económico - OCDE, o país enviou, em 2010, 34.510 estudantes para um período de estudos no exterior.” (SILVA, 2013, p. 14).

Sob esse ponto de vista, Luna e Sehnem (2013) inferem que programas de mobilidade estudantil se destinam a construir um espaço acadêmico cada vez mais competitivo e situado internacionalmente e de modo intercultural. Além do estudo científico e o currículo estarem mais internacionalizados, os intercambistas carregam consigo a necessidade de descobertas e socialização ligada à realidade global.

O crescimento dos programas de mobilidade, no país, motivou o interesse por pesquisas sobre o tema (LIMA et al., 2009; MAZZA, 2011; GUIMARÃES, 2013; SPEARS, 2014; entre outros) que investigaram sua importância, seus benefícios e desafios, apontando que a mobilidade estudantil internacional, no Brasil, é um fenômeno complexo e, por isso, cria uma abertura para novos estudos sobre o tema. 


\section{PROCEDIMENTOS DA PESQUISA}

Esta pesquisa de natureza qualitativa (FLICK, 2009) trata do intercâmbio estudantil e objetivou reunir e analisar experiências sociais e interculturais de estudantes de administração da FAGEN/UFU no tocante ao período vivido em mobilidade internacional. Os entrevistados eram estudantes da Universidade Federal de Uberlândia, uma instituição pública federal que tem empregado esforços para fortalecer a mobilidade internacional de seus estudantes. A Diretoria de Relações Internacionais e Interinstitucionais (DRII) da Universidade Federal de Uberlândia gerencia os programas de mobilidade de interesse da instituição. Como forma de mobilidade internacional, a UFU utiliza o Programa Ciência sem Fronteiras para enviar seus estudantes para países estrangeiros, além de convênios específicos com países da América do Sul e Europa e com o Canadá, igualmente, com a China. O programa tem como objetivo promover a consolidação, expansão e internacionalização da ciência e tecnologia, da inovação e da competitividade brasileira por meio do intercâmbio e da mobilidade internacional. Quanto à mobilidade nacional, há o Programa da Associação Nacional dos Dirigentes das Instituições Federais de Ensino Superior (ANDIFES) - que possibilita ao estudante estudar em outra Universidade Federal de Ensino Superior no país.

Para compor o corpus de pesquisa, foi utilizado um roteiro de entrevista semiestruturada (FLICK, 2009) com oito estudantes do curso de Administração da UFU que participaram dos programas de Mobilidade Internacional, nos últimos dois anos (Quadro 1). 
Quadro 1 Perfil dos entrevistados

\begin{tabular}{|c|c|c|c|c|c|c|}
\hline Noмe & IDADE & Sexo & $\begin{array}{l}\text { País De } \\
\text { Destino }\end{array}$ & $\begin{array}{c}\text { TEMPO DE } \\
\text { INTERCÂMBIO } \\
\text { (MESES) }\end{array}$ & UNIVERSIDADE & BoLsA \\
\hline Bianca & 24 & $\mathrm{~F}$ & EUA & 7 & $\begin{array}{c}\text { University of } \\
\text { California, Davis }\end{array}$ & Não \\
\hline Davi & 23 & M & Holanda & 12 & $\begin{array}{c}\text { NHTV Breda } \\
\text { University of } \\
\text { Applied Sciences }\end{array}$ & Não \\
\hline Fernando & 24 & M & Portugal & 6 & $\begin{array}{l}\text { Universidade } \\
\text { do Algarve }\end{array}$ & Não \\
\hline Laura & 24 & $\mathrm{~F}$ & França & 12 & $\begin{array}{c}\text { Université de } \\
\text { Franche - Comté }\end{array}$ & Não \\
\hline Natália & 24 & $\mathrm{~F}$ & Holanda & 7 & $\begin{array}{c}\text { NHTV Breda } \\
\text { University of } \\
\text { Applied Sciences }\end{array}$ & Não \\
\hline Rafaela & 23 & F & Espanha & 5 & $\begin{array}{c}\text { Universidade } \\
\text { de Vigo }\end{array}$ & Não \\
\hline Sietst & 25 & M & Holanda & 11 & $\begin{array}{c}\text { NHTV Breda } \\
\text { University of } \\
\text { Applied Sciences }\end{array}$ & Não \\
\hline Washington & 23 & M & Espanha & 5 & $\begin{array}{c}\text { Universidade de } \\
\text { Vigo }\end{array}$ & Não \\
\hline
\end{tabular}

Os entrevistados referiram idades entre 23 e 25 anos, sendo, quanto ao gênero, $50 \%$ de cada um. Os países de destino foram Estados Unidos, Holanda, Portugal, França e Espanha, nações com as quais a UFU mantém um acordo bilateral de mobilidade estudantil. O tempo médio de intercâmbio durou aproximadamente oito meses e nenhum dos entrevistados recebeu bolsa.

O roteiro de entrevistas foi elaborado com base no objetivo da pesquisa, portanto, focalizando motivações, expectativas, desafios, benefícios percebidos e lembranças importantes. As entrevistas foram realizadas entre maio e junho de 2015 e tiveram duração média de 30 minutos. As entre- 
vistas foram gravadas com o consentimento dos entrevistados e, posteriormente, foram transcritas, resultando em 32 laudas. É importante destacar que os entrevistados foram identificados por meio de nomes fictícios por eles atribuídos. Ao iniciar as entrevistas, solicitava-se aos entrevistados que informassem com qual nome gostariam de ser nominados, e, assim, tais nomes são usados para identificá-los nesta pesquisa.

Após a realização e transcrição das entrevistas, a análise de conteúdo temática foi aplicada, pois, segundo Bardin (1979), é um método de pesquisa que tem como foco a descrição objetiva, sistemática e quantitativa do objeto manifesto da comunicação. Inicialmente, na etapa da pré-análise, realizou-se a leitura flutuante e o material foi organizado a fim de ser analisado com o intuito de transformá-lo em operacional, assim, estruturando as informações iniciais, como a determinação das temáticas para a unidade de análise.

Na segunda etapa, foram estabelecidos os códigos de acordo com as categorias de análise previamente indicadas, para tanto, considerando os objetivos da pesquisa e o roteiro de entrevista, quais sejam: motivações, expectativas, desafios, benefícios percebidos e lembranças importantes. $\mathrm{Na}$ etapa de tratamento dos resultados, inferência e interpretação, os trechos que correspondem às categorias analíticas foram agrupados para possibilitar a análise dos temas mais recorrentes, que são apresentados e discutidos a seguir. 


\section{EXPERIÊNCIAS SOCIAIS E INTERCULTURAIS DOS ESTUDANTES}

Nesta seção, apresentam-se os resultados da pesquisa. Os entrevistados foram indagados sobre as motivações, as expectativas, as experiências, os desafios e as lembranças importantes que tiveram durante a realização da mobilidade estudantil.

\section{MOTIVAÇÕES DOS ESTUDANTES PARA REALIZAREM A MOBILIDADE INTERNACIONAL}

Os principais motivos citados pelos entrevistados foram o desejo de aprimorar a língua estrangeira e conhecer outros países. O aprimoramento da língua estrangeira foi citado por sete dos oito entrevistados como o principal motivo para estudar no país de destino.

Entre os entrevistados, foi possível notar que a maioria desejava aprimorar o idioma que havia estudado e começado a aprender no Brasil, como forma de adquirir um diferencial profissionalmente. Washington, por exemplo, referiu que "queria aprimorar o espanhol porque era mais fácil de aprender e dominar mais rápido e havia feito um cursinho e não tinha o domínio da língua, queria ter um diferencial", e Rafaela expôs que: "Eu já estava estudando a língua espanhola, por isso, queria fazer o intercâmbio para desenvolver a língua”.

Já Fernando preferiu realizar o intercâmbio estudantil em um país onde o idioma fosse semelhante ao do Brasil para ter facilidade na hora da comunicação com os outros indivíduos. No seu depoimento, Fernando conta que: "Escolhi este país por causa da língua ser parecida com a do Brasil, quando você chega lá é uma facilidade falar a mesma língua, para pedir ajuda, se comunicar melhor". Para os entrevistados, o idioma do país de destino foi característica importante na escolha, todos desejavam ter um diferencial que contribuísse, futuramente, para a vida profissional. Os entrevistados afirmaram que gostariam de obter fluência no idioma, como, por exemplo, Davi: "Na época, era o único lugar onde a UFU tinha convênio e que era de língua inglesa, eu queria, no mínimo, ganhar a fluência em uma língua diferente”. 
Para Lima e Contel (2008), o intercâmbio estudantil é uma experiência única, visto que favorece a aprendizagem de línguas estrangeiras com base no contato diário com o idioma e todo o contexto intercultural que uma experiência dessa natureza proporciona. O desejo de conhecer outro país e uma nova cultura foi justamente outra motivação bastante citada pelos estudantes como um fator importante na escolha de fazer um intercâmbio internacional.

Os depoimentos dos entrevistados apontam o desejo de conhecer algo diferente e pessoas e culturas distintas que contribuíssem profissionalmente para eles. Davi foi motivado por conhecer novas culturas: "Eu queria ter a experiência de estudar em um país diferente, buscar novas culturas, ter um contato com pessoas da minha área em outros países, aumentar meu network".

A maioria dos entrevistados teve preferência por países da Europa, cujas nações são desenvolvidas e estavam entre as opções de intercâmbio que a UFU possuía convênio e oferecia no momento, como é o caso de Rafaela: "Eu já tinha curiosidade de conhecer outro país, a UFU tinha convênios com outros países na América do Sul, mas eu queria ir para a Europa”. Por meio da mobilidade, é possível aprender melhor as culturas distintas, vivenciando-as no dia a dia. Além disso, é uma experiência que pode oferecer benefícios profissionais para os estudantes, pois potencializa o desenvolvimento de sua habilidade de adaptação, considerando-se o novo contexto no qual se inserem, além de aprimorar capacidades linguísticas.

Esses resultados diferem daqueles encontrados por Silva, Lima e Riegel (2013, p.248), que pesquisaram estudantes que escolheram o Brasil para a mobilidade acadêmica. Esses, segundo os autores, fizeram sua escolha por motivações pessoais e acadêmicas, mas, também, em virtude da "imagem do país como um diferencial entre outras opções de destino”. 


\section{EXPECTATIVAS DOS ESTUDANTES QUANTO À EXPERIÊNCIA DE MO- BILIDADE INTERNACIONAL}

As principais expectativas apontadas pelos estudantes entrevistados foram: independência, viajar, conhecer o novo (pessoas e lugares), um nível de ensino mais elevado do que no Brasil e adquirir mais conhecimento.

Os depoimentos dos estudantes entrevistados, de maneira geral, ressaltam a expectativa de alcançar a liberdade e independência, que, normalmente, os jovens almejam muito. Assim como o desejo de conhecer melhor a si próprios, por meio do descobrimento de novas culturas e indivíduos, pois o intercâmbio proporciona tais oportunidades, caso saibam aproveitar ao máximo essa experiência enriquecedora.

Natália mencionou a obtenção de experiência de liberdade e de se conhecer melhor, de "saber como eu ia me virar, queria, também, desenvolver o inglês, e para contribuir profissionalmente, porque eu acreditava e continuo acreditando que o intercambio é um diferencial". Sietst, também, referenciou a expectativa quanto à independência: "Eu queria muito morar sozinho, ter essa vivência em outras culturas, viajar e ter mais independência”.

Os demais entrevistados mencionaram a expectativa de viajar e conhecer o novo, e Fernando relatou seu desejo de "vivenciar culturas diferentes, conhecer pessoas novas, queria, também, conhecer outros lugares, viajar bastante. Craide e Silva (2012) afirmam, justamente, que a mobilidade estudantil fornece a oportunidade do encontro com um contexto culturalmente diferente em relação às suas origens. E esse encontro entre diferentes culturas no mesmo ambiente acadêmico torna-se positivo, pois todos são beneficiados pela diferença de opiniões.

A expectativa de que, no exterior, o nível de ensino seja mais elevado foi compartilhada por Rafaela e Washington. Rafaela imaginava que o ensino no exterior seria mais rígido que no Brasil, mas não viu diferenças quanto a isso. E Washington ficou decepcionado:

Eu imaginava que as aulas me agregariam muito, que seria diferente do que estamos acostumados aqui no Brasil. Mas eu fiquei um pouco de- 
cepcionado, eu vi que nem é tão diferente daqui, existe professor realmente interessado em dar aula, existe professor que não [...] Mas foi bom para conhecer, porque a gente critica muito o Brasil, mas a gente não fica para trás em relação à Europa.

No tocante ao nível de ensino, foi possível detectar, por meio dos depoimentos, que alguns entrevistados se decepcionaram com o nível de ensino europeu. Os estudantes tinham uma visão de que o Brasil possuía um nível de ensino bem inferior ao dos países europeus devido ao fato de ser uma nação subdesenvolvida, mas, ao deparar-se com a realidade específica da instituição escolhida, perceberam que a universidade e os estudantes europeus não eram tão superiores como imaginavam.

Entretanto um ponto positivo que se destacou foram as aulas práticas que tiveram, quando era possível compreender, na prática, as teorias estudadas anteriormente. Barblan (2002) afirma que o principal objetivo da mobilidade acadêmica é ampliar o conhecimento dos estudantes despertando um sentimento de cidadão do mundo. Ainda na parte de ensino, os entrevistados citaram como uma das principais expectativas o desejo em adquirir novos conhecimentos. Dos oito entrevistados, cinco mencionaram que queriam aprender coisas e conteúdos diferentes daqueles que, normalmente, estudavam e vivenciavam no Brasil, pois almejavam um crescimento e amadurecimento tanto pessoal como profissional, conforme depoimento da estudante Natália:

Esperava que fosse além de uma experiência acadêmica, que eu fosse aprender alguma coisa diferente do que tinha aqui na UFU, para me acrescentar em questão de carreira profissional, eu queria poder viajar, conhecer gente de todos os lugares.

Então eu queria ter uma relação com outras culturas, entender quais são as diferenças que podemos encontrar, até para quando voltar ao Brasil ter uma mente mais aberta.

Os demais depoimentos, também, apontam para a expectativa de ampliar o conhecimento. Davi, por exemplo, tinha a expectativa de fazer 
um dos melhores cursos em logística do mundo, pois a escola de destino já foi premiada nessa área várias vezes, então, conforme suas palavras, "transmitia confiança pela qualidade do curso". O crescimento pessoal e a vivência internacional são alguns resultados alcançados por aqueles que decidem participar de um intercâmbio em face da exigência cada vez maior do mercado de trabalho. A vivência em outro país concede uma visão diferenciada sobre diversos assuntos, amplia o conhecimento e fornece autoconfiança e maturidade, qualidades que tornam o indivíduo mais interessante para o futuro empregador.

Como Stallivieri (2003) explica, a internacionalização da educação é um dever das universidades. Os estudantes apontaram que as universidades de destino estavam preparadas para recebê-los, o que sugere o reconhecimento dessa responsabilidade, pois não basta a firmação de acordos e, ao relatar suas experiências, evidenciam que adquiriram um entendimento mais amplo da dinâmica social e tinham a expectativa de aprender o novo. De acordo com Contel e Lima (2007), o desejo de aprender sobre novas coisas adquiriu um novo significado, pois as condutas do dia a dia demandam uma variedade de conhecimento para resolver os problemas que surgem no cotidiano. Fernandez (2002) afirma que a mobilidade é um meio de combate em favor da independência. Isso foi comum na fala dos entrevistados quando expuseram suas motivações.

\section{DESAFIOS ENFRENTADOS PELOS ESTUDANTES}

Os desafios citados pelos estudantes foram: o idioma, as interações com os nativos, a moradia, a saudade da família, as baixas temperaturas, as diferenças culturais e o estágio na empresa internacional. Encarar desafios não é uma tarefa fácil, porém, de acordo com Lima et al. (2009), a mobilidade internacional amplia o capital intelectual e contribui para o desenvolvimento de competências valorizadas pelo mercado de trabalho, conforme favorece o amadurecimento emocional dos jovens. Entre os desafios mais citados pelos entrevistados, a dificuldade em conseguir falar e entender o novo idioma foi, com certeza, o mais citado. No entanto esse desafio foi superado e os estudantes conseguiram desenvolver a habilidade de fluência no 
idioma do país hospedeiro, como conta Natália, "mas ao final do primeiro mês, eu percebi que já estava entendendo muito mais fácil e conseguia acompanhar as aulas sem dificuldades, apenas um termo técnico às vezes que tinha maior dificuldade, minha escrita melhorou também".

De acordo com as experiências descritas pelos entrevistados relativamente ao domínio do idioma, detectou-se que a dificuldade maior foi a questão da fala, em que a maioria conseguia compreender o que estava sendo dito, porém, na tentativa de expressar-se, encontrava certa dificuldade, principalmente, no primeiro mês de mobilidade. Boa parte dos estudantes relata que, nos primeiros dias de intercâmbio, sentia-se travada e não conseguia falar com tranquilidade o novo idioma, pois ainda havia insegurança com o que não se dominava. Mas, depois de poucas semanas de convívio com o idioma, a comunicação tornava-se quase que automática e eles se sentiam seguros em expressar-se falando uma nova língua.

Meu único problema com a língua é que, no início, eu era muito travado, mas depois de um tempo já falava sem pensar, passou a ser automático. Na minha turma não tinha nenhum brasileiro então eu falava muito inglês, para fazer trabalho, sair, tudo era em inglês, por isso consegui desenvolver rápido. (SIETST).

Outro desafio mencionado pelos entrevistados está relacionado com a interação com os colegas de sala. Alguns relatos deixam claro que, inicialmente, houve certo estranhamento quanto ao comportamento dos estudantes nativos do país. Acostumados com o modo de comportar-se dos brasileiros, alguns se sentiram desprezados com o comportamento mais reservado dos europeus, em virtude de boa parte do povo brasileiro mostrar-se espontânea e receptiva.

Senti-me desprezado no início principalmente pelos nativos da cidade, que parece que quem vinha de fora era inferior a eles, como eles já estavam acostumados com intercambistas não davam muita bola. Depois de um tempo, ganhamos um certo reconhecimento deles pois mostramos que éramos capazes assim como eles. (WASHINGTON) 
Muitos deles relataram algumas dificuldades que tiveram em relação ao convívio na universidade. Rafaela considerou a dificuldade de se enturmar e conseguir interagir com as pessoas, o que não aconteceu com Natália, que tinha suas ideias aceitas pelo grupo: "eles aceitavam as minhas ideias para o trabalho, mas demorava mais, eu tinha que ser bem convincente, mas em algumas partes, como financeira, a gente conseguia conversar no mesmo nível”.

Apesar das diferenças culturais, desafios como estes são importantes e beneficiam o amadurecimento dos estudantes que se aventuram em um intercâmbio estudantil. Tomazzoni e Oliveira (2013) afirmam que o intercâmbio proporciona desenvolvimento pessoal em ambiente desconhecido. Uma das dificuldades é manter o próprio bem-estar no país estrangeiro. Com a mobilidade internacional, o estudante desenvolve habilidades que contribuem para o crescimento de sua carreira profissional.

Outra dificuldade citada por três dos oito entrevistados foi o desafio em encontrar moradia devido a imprevistos que colocaram à prova suas habilidades em resolver problemas. Para Natalia, a moradia foi o maior problema encontrado:

Foi o maior problema que tive lá, porque só tinha contratos de seis meses ou de um ano e eu ia ficar lá sete meses por causa do curso. Todos os quartos que eu olhava na internet eram longe e mais caro, e meu prazo foi acabando, minha sorte foi que descobri uma garota que ia ficar fora fazendo mestrado quatro meses, então, aluguel o quarto dela que ia ficar vago.

Para Hill, Lynch e Dalley-Trim (2002), a mobilidade inclui oposição e conflito com as diferenças, o que requer inúmeras habilidades para se adaptar e desenvolver novas competências. A mobilidade acadêmica caracteriza-se por uma maneira de aprendizado que amplia os horizontes do indivíduo.

Três entrevistados ressaltaram que o desafio de encontrar moradia foi algo que os afligiu, tornando-se um obstáculo difícil de vencer. Dois deles encontraram tal dificuldade logo no início da mobilidade, o que conside- 
raram uma verdadeira aventura. Ainda quanto a esse aspecto, os costumes da população dos países de destino, também, influenciaram no encontro da moradia, conforme depoimento que segue:

Por ser homem, tive um pouco de dificuldade em encontrar apartamento para morar, pois dão preferência para garotas, por acreditar que dão menos trabalho, fazem menos bagunça. Nos primeiros dias, foi difícil encontrar um lugar para morar, mas dei sorte de conseguir um bom lugar, bem conservado. (WASHINGTON)

Todavia, no final, tudo acabou resolvendo-se e esses desafios contribuíram para o crescimento desses estudantes. Conforme Hill, Lynch e Dalley-Trim (2012), a mobilidade estudantil não se trata apenas de viver um período no exterior, mas de um meio de desenvolvimento pessoal, visto que essas viagens colaboram para o desenvolvimento de habilidades comunicacionais.

A saudade da família, igualmente, foi um desafio para os estudantes entrevistados. Quando questionados sobre o relacionamento com a família durante o tempo em mobilidade internacional, metade dos entrevistados afirmou que a saudade da família se sobressaiu nos primeiros dias de intercâmbio, mas, com o tempo, foram acostumando-se a conviver com a saudade. Além disso, as redes sociais foram importantes aliadas no combate contra a saudade da família, por meio da qual era possível manter contato constante com seus familiares. Apesar de aprender a conviver bem com essa saudade, havia épocas que eram mais difíceis de suportar, como em datas comemorativas ou nas tardes de domingo, mas o uso de tecnologias da informação e o apoio dos colegas contribuíram para amenizar esses desafios, como conta Laura: "não foi algo que me atrapalhou, porque um vai se apoiando no outro, está todo mundo na mesma situação, mas no domingo à tarde era a hora de maior depressão, então não ficávamos sozinhos".

Alguns entrevistados afirmaram que procuravam se ocupar e aproveitar a viajem ao máximo para não sentirem tanta saudade da família, como foi o caso de Rafaela: 
Estando lá eu mantinha contato sempre. Em relação a saudade eu viajei bem tranquila, mas quando cheguei lá senti muita falta, o mais difícil para mim foi o primeiro mês, porque até eu me acostumar e me adaptar em uma casa nova, rotina diferente. Mas depois foi mais tranquilo, comecei a interagir mais e a estar sempre ocupada.

Washington conta que sentiu muita saudade e foi um desafio muito maior pela relação que tinha com os pais. Ele, igualmente, utilizou-se das redes sociais mediadas pela internet:

A saudade da família foi um desafio desde o começo, [...]. Estando lá foi muito fácil a comunicação, por meio de WhatsApp, Skype, se eu tivesse ido uns períodos antes não tinha essas coisas, esses aplicativos, foi fácil manter o contato, falava com eles toda semana. No início, tinha contato com minha mãe quase todo dia, depois, ficou sendo semanal, meu irmão mais velho estava casando, eu até vim para o casamento, fiquei uma semana e voltei porque ainda tinha prova lá, as atividades dela aqui eram normais corriqueiras, então ela não ficava $24 \mathrm{~h}$ comigo, mas falava com ela toda semana.

Apesar da saudade de casa e da família sempre existir, ao viver uma experiência internacional, o estudante precisa adaptar-se a um país com outra cultura, outras realidades sociais e, por conseguinte, possivelmente, iniciará uma revisão de valores (SILVA, 2013). Assim como a locomoção, algo bem diferente do Brasil foi o clima frio, citado por quatro entrevistados, que, muitas vezes, tornava-se um desafio para estudantes acostumados a temperaturas de países tropicais. Mas todos alegaram que, apesar do clima frio ser um desafio, ele não atrapalhou na realização de suas atividades diárias.

Um desafio enriquecedor foi a oportunidade de fazer estágio durante o intercâmbio estudantil. Dois dos oito entrevistados tiveram e conseguiram alcançar tal oportunidade, conforme os relatos de Bianca e Laura. De acordo com os depoimentos, o maior desafio vivenciado durante a mobilidade foi o estágio internacional. Ambas ressaltam a importância que esta experiência de trabalhar em uma empresa internacional teve em seu crescimento pessoal e profissional. 
O desafio maior foi o estágio. Depois de uns dois meses de estágio eu comecei a me soltar bem mais e me sentir mais segura. Aqui no Brasil eu já havia feito vários estágios, mas lá foi tudo diferente, então eu fui com a intenção de fazer o estágio, mas não tinha ideia se iria conseguir, então me considero uma aventureira, e foi melhor do que eu imaginava. O ambiente coorporativo às vezes é bem complicado, muitas vezes todo mundo saía e me deixava sozinha lá na frente para atender os clientes que chegavam na empresa, e eu suava frio porque não sabia direito o que falar e tinha que atender telefone, mas foi muito bom, aprendi muito. (BIANCA).

É possível notar que o estágio proporcionou um grande aprendizado para as estudantes, pois, em algumas situações, era necessário mostrar segurança e amadurecimento que ainda estavam sendo adquiridos. Algo difícil em uma empresa internacional é a adaptação às diferenças culturais, conforme depoimento precedente, cujos colaboradores mostravam um comportamento exclusivamente profissional e não misturavam vida pessoal com profissional. As diferenças culturais proporcionam aos estudantes intercambistas o desenvolvimento de um entendimento mais profundo em relação aos conflitos do mundo, uma maior compreensão de outras culturas, aprimoramento das habilidades de comunicação intercultural, melhora na autoimagem e no perfil profissional, bem como aprimoramento do idioma.

\section{BENEFÍCIOS PERCEBIDOS COM A MOBILIDADE}

Os entrevistados foram questionados sobre os benefícios adquiridos em virtude da mobilidade estudantil internacional. Nota-se que todos consideram a mobilidade como uma importante experiência de vida que acrescentou bastante tanto no lado profissional como pessoal. Por meio do intercâmbio, o aluno consegue perceber que pode alcançar seus objetivos, mas, para isso, é necessário ter foco e determinação. Citaram como benefícios o ganho de conhecimento, o amadurecimento, as novas amizades internacionais e as diferentes formas de ver o mundo. Para Davi, a mobilidade ampliou sua experiência de vida: 
Ganhei muita experiência de vida, maturidade, mais conhecimento na língua inglesa, independência, conhecimento que a gente nunca esquece. Fiz um curso marítimo em um cruzeiro, obtive informações sobre a área na qual eu trabalho que é a logística e um pouco de economia, então não tem nem como mensurar o ganho que tive.

Craide e Silva (2012) pontuam que é necessário capacitar os profissionais e estudantes no tocante ao encontro e convívio com as dificuldades e diferenças para que consigam compreendê-las e, muitas vezes, aceitá-las. O convívio com a variedade plural cria a necessidade de um melhor entendimento do outro, de solucionar problemas e gerar novas oportunidades juntos, além de beneficiar a mobilidade externa e interna da sociedade (FREITAS, 2009).

Os estudantes perceberam mudanças ocorridas no pós-mobilidade internacional. Em relação às mudanças que a mobilidade proporcionou aos entrevistados, algumas destacadas foram quanto ao fato de ter agregado valor na vida profissional de cada um, o que facilitou na hora de encontrar trabalho. Além disso, eles ressaltaram maior habilidade em resolver conflitos e mudança na maneira de ver o mundo, assim, alcançando um crescimento pessoal.

O intercâmbio mudou um pouco a minha perspectiva de vida, o que eu gostaria de ser agora eu vejo de uma forma diferente e me ajudou a enxergar realmente como é o nosso Brasil, porque, quando vivemos em outro país, a gente vê outra realidade, outra cultura, outra forma de organização da sociedade. (RAFAELA).

Lima et al. (2009) declaram que a mobilidade internacional amplia o capital intelectual e contribui para o desenvolvimento de competências valorizadas pelo mercado de trabalho, à medida que favorece o amadurecimento emocional dos jovens.

O crescimento pessoal e a vivência internacional são alguns resultados alcançados por aqueles que decidem participar de um intercâmbio. Ademais, a vivência em outro país concede uma visão diferenciada sobre 
diversos assuntos, amplia o conhecimento, fornece autoconfiança e maturidade, qualidades que tornam o indivíduo mais interessante para o futuro empregador. Silva (2013) completa aduzindo que, ao viver uma experiência internacional, o estudante precisa adaptar-se a um país com outra cultura, outras realidades sociais e que, possivelmente, iniciará uma revisão de valores.

\section{LEMBRANÇAS IMPORTANTES CONTADAS PELOS ENTREVISTADOS}

Os entrevistados reportaram cinco principais experiências mais importantes vivenciadas: a recepção na universidade, a adaptação à moradia, a locomoção, os laços de amizade e as marcas. A primeira experiência citada pelos entrevistados foi sobre a recepção na universidade escolhida para o intercâmbio.

De forma geral, os oito entrevistados afirmaram que foram bem-recebidos na instituição de ensino, é possível destacar que o fato de as universidades de destino serem internacionais, sempre com vários intercambistas, por perto, tornou a recepção mais fácil e acolhedora, pois muitos estudantes estavam na mesma situação. Além disso, os entrevistados citaram a atenção dada a eles pelos representantes das instituições, principalmente, nos primeiros dias de adaptação. Sietst conta que: "Fui muito bem-recebido, na época, eles tinham um grupo de estudantes que ficava por conta dos alunos internacionais, um dos alunos chegou a nos buscar no aeroporto de Amsterdã e nos levou para onde a gente ia ficar, foram bem receptivos".

Stallivieri (2003) ressalta que a internacionalização da educação é um dever justamente das universidades. Oferecer aos seus estudantes a possibilidade de experiências internacionais para que se tornem mais qualificados para o mercado mundial faz parte das atribuições das instituições que se propõem a obter os benefícios da internacionalização. Quanto à adaptação na moradia, os depoimentos apontam que os entrevistados se sentiram bem-acolhidos e confortáveis em sua nova moradia. Rafaela, que morava com estudantes estrangeiros, considerou a experiência divertida: "Foi bem legal e divertido a gente se conhecer depois, porque nos tornamos uma 
família, saíamos juntos, assistíamos a filmes, cozinhávamos juntos, nos tornamos um grupo bem unido".

Entretanto três deles citaram desafios que enfrentaram, principalmente, nos primeiros dias de adaptação, desafios esses que estão relacionados a diferenças e costumes culturais, conforme os depoimentos dos entrevistados, como é o caso de Washington, que sentiu dificuldade em relacionar-se com uma das colegas: "dividi o apartamento com mais três pessoas, entre elas uma alemã, que foi a única que não me dei muito bem e, às vezes, havia alguns conflitos, pois ela era mais fria”.

Essa interação e esse convívio com diferentes costumes e culturas são enriquecedores. De acordo com Tomazzoni e Oliveira (2013), o intercâmbio proporciona experiência para ambas as partes, tanto para o indivíduo que vive outra realidade quanto para quem o recebe. Com relação à vivência no país de destino, a locomoção foi algo bastante mencionado pelos entrevistados, que expressaram como era o deslocamento no país de destino. Os depoimentos apontam que os meios de transportes eram muito diferentes do Brasil, alguns citaram tecnologias que tornavam a viagem mais agradável, como ar-condicionado nos ônibus, assim como música, aquecedores, aplicativos que facilitavam o acompanhamento dos transportes. Algo interessante é o fato de deslocarem-se bastante a pé ou de bicicleta, algo que não é tão incentivado e respeitado no Brasil. Além disso, ficou claro, a partir dos relatos, que a segurança contribui bastante para a utilização desses tipos de transportes, assim como a estrutura geográfica do país.

Para ir para a universidade tínhamos que pegar um ônibus, porque ela fica fora da cidade, os ônibus eram bem-organizados e confortáveis, quando chegamos ainda estava no verão, então tinha ar-condicionado nos ônibus, sinal de internet, tocava rádio dentro do ônibus. Quando começou o frio, havia o sistema de aquecedor, era bem diferente do que a gente vê aqui no Brasil, lá não tem cobrador dentro do ônibus, pagava para o próprio motorista ou passava o cartão na máquina. (RAFAELA).

Os laços de amizade, igualmente, foram mencionados. Quando questionados sobre a interação com indivíduos de diferentes culturas, todos res- 
saltaram o estabelecimento espontâneo de amizades com intercambistas de outros países que se encontravam na mesma situação.

Fiz bastantes amigos porque, na Europa, como um todo, tem um grupo que é responsável por acolher os estudantes Erasmus, lá essa associação era bem desenvolvida e eram muito competentes nisso, sempre tinha integração, toda semana tinha uma programação, tinha auditórios, reuníamos todo mundo para assistir filmes. Eram umas quarenta a cinquenta pessoas que se reuniam sempre, então isso ajudou muito, eu fiquei bem próxima de muita gente diferente, nós viajamos juntos. (LAURA).

Segundo Freitas (2009), a mobilidade do indivíduo contribui para elevar seu capital simbólico, composto pelo capital cultural - conjunto de certificados, idiomas falados, maneira de comunicar conhecimentos adquiridos - e capital social, que é formado pelas redes de relacionamentos do indivíduo ou grupo. Conforme os depoimentos, os estudantes entrevistados expressaram que fizeram amizades mais fortes entre os próprios intercambistas e não com os indivíduos nativos do país de destino. A maioria alegou que, por estar em um país diferente, com cultura e pessoas variadas e distintas, os estudantes em mobilidade estavam mais abertos ao diferente, ao novo e, desse modo, tornavam-se mais sociáveis e simpáticos, assim, formando uma espécie de comunidade.

Foi, ainda, solicitado aos estudantes que contassem sobre um evento que tenha se tornado uma lembrança importante para eles. As lembranças estavam relacionadas, em sua maioria, com as viagens realizadas para conhecer outras cidades além daquela onde realizavam o intercâmbio. Nos oito depoimentos, os entrevistados retrataram aventuras, "perrengues", encontro com o desconhecido, a solidariedade e, novamente, os laços de amizade que foram criados nesse período. Natália conta que, ao viajar sozinha para Barcelona, perdeu o horário do ônibus de retorno e viu-se obrigada a ficar andando pelas ruas do centro na madrugada, o que ocasionou certo desconforto: "Às vezes, viam alguns homens me chamando para sair, ir em festas, e eu não falava que era brasileira, porque eles iam achar que eu era prostituta, eu falava que era da Holanda”. Já Fernando conta a expe- 
riência de ser bem-tratado pela família de um amigo do Marrocos e outro da Hungria:

Nós ficamos realmente impressionados com a solidariedade deles, como ele era um guia nos levou para conhecer o deserto, fizemos todo o percurso que ele costumava fazer com os turistas que ficam hospedados na casa dele. Aprendemos bastante, foi uma boa experiência. Na Hungria, também, ficamos hospedados na casa de uma família muito humilde, o que me impressionou foram essas pessoas tão humildes e tão solidárias, isso me deixou muito feliz e satisfeito, porque eu vi que não precisava gastar muito para ter uma boa experiência fora daqui, só de ficar na casa dessas famílias e conviver com a cultura deles já me agregou bastante.

Lima e Nascimento (2012) inferem que a mobilidade é uma experiência de sair de um mundo restrito e ampliar horizontes e conviver com culturas diferentes que proporcionam uma visão do mundo mais ampla, o que contribui para uma formação acadêmica e pessoal mais rica e diferenciada. 


\section{MARCAS DAS EXPERIÊNCIAS SOCIAIS E INTERCULTURAIS}

De forma resumida, o Quadro 2 reúne as marcas das experiências dos estudantes entrevistados, as quais refletem os resultados desta pesquisa.

Quadro 2 Experiências Sociais e Interculturais dos Entrevistados

\begin{tabular}{|c|c|}
\hline Categorias & EXPERIÊNCIAS \\
\hline $\begin{array}{l}\text { Motivações para realizar } \\
\text { o intercâmbio }\end{array}$ & $\begin{array}{l}\text { Desejo de aprimorar a língua estrangeira e conhecer } \\
\text { outros países }\end{array}$ \\
\hline $\begin{array}{l}\text { Expectativas dos } \\
\text { estudantes }\end{array}$ & $\begin{array}{l}\text { Independência, viajar, conhecer o novo (pessoas e } \\
\text { lugares), um nível de ensino mais elevado do que no } \\
\text { Brasil e adquirir mais conhecimento }\end{array}$ \\
\hline $\begin{array}{l}\text { Desafios enfrentados no } \\
\text { período de mobilidade }\end{array}$ & $\begin{array}{l}\text { O idioma, as baixas temperaturas, as interações com } \\
\text { os nativos, saudade da família, diferenças culturais e } \\
\text { o estágio na empresa internacional }\end{array}$ \\
\hline Benefícios percebidos & $\begin{array}{l}\text { O ganho de conhecimento, amadurecimento, novas } \\
\text { amizades internacionais e diferentes formas de ver } \\
\text { o mundo }\end{array}$ \\
\hline \multirow[b]{2}{*}{ Lembranças } & $\begin{array}{l}\text { A recepção na universidade, a adaptação à moradia, } \\
\text { a locomoção, os laços de amizade e as marcas }\end{array}$ \\
\hline & $\begin{array}{l}\text { Marcas: aventuras, "perrengues", encontro com } \\
\text { desconhecido, a solidariedade e, novamente, os } \\
\text { laços de amizade que foram criados nesse período }\end{array}$ \\
\hline
\end{tabular}

O conceito de mobilidade, conforme Freitas (2009), refere-se às disposições e habilidades que conduzem o indivíduo a relacionar-se com um outro, distinto de si, proporcionando-lhe ampliar sua bagagem profissional e pessoal. Os estudantes entrevistados ressaltaram o desenvolvimento dessas habilidades, além de apontarem, ainda, para sua aptidão em mudar de um local de estudos para outro, por diversas motivações.

Como Stalliveiri (2003) e Paula (2011) afirmam, a internacionalização da educação é um dever das universidades. Os estudantes apontaram que as universidades de destino estavam preparadas para recebê-los, o que su- 
gere o reconhecimento dessa responsabilidade, pois não basta a firmação de acordos.

Conforme a literatura revisada para discutir esses resultados, os estudantes, ao relatar suas experiências, evidenciam que adquiriram um entendimento mais amplo da dinâmica social e tinham a expectativa de aprender o novo. De acordo com Contel e Lima (2007), o desejo de aprender sobre novas coisas adquiriu um novo significado, pois as condutas do dia a dia demandam uma variedade de conhecimento para resolver os problemas que surgem no cotidiano. Fernandez (2002) afirma que a mobilidade é um meio de combate em favor da independência. Isso foi comum na fala dos entrevistados quando expuseram suas motivações.

Como Craide e Silva (2012) mencionam, é preciso capacitar os estudantes para lidar com as diferenças. Isso foi possível no intercâmbio, pois os estudantes se depararam com diferenças culturais, sendo elas comportamentais e estruturais. Ao conviver com a pluralidade relatada nos depoimentos dos entrevistados, evidencia-se o que Freitas (2009) menciona sobre a criação da necessidade de um melhor entendimento do outro, de solucionar problemas. Isso foi retratado por vários estudantes que disseram que, em algum momento, "tiveram que se virar" para resolver determinadas situações, e, ainda, no convívio com culturas diferentes, tiveram de adaptar-se.

Os resultados, também, apontam para o aumento do capital simbólico dos estudantes entrevistados. Para Freitas (2009), o capital simbólico é composto pelo capital cultural - conjunto de certificados, idiomas falados, maneira de se comunicar conhecimentos adquiridos - e capital social, que é formado pelas redes de relacionamentos do indivíduo ou grupo. Todos esses aspectos foram mencionados nas entrevistas.

De modo geral, os estudantes mostraram ter percebido os benefícios da mobilidade conforme a revisão da literatura: desenvolvimento pessoal, ampliação do conhecimento, desenvolvimento de habilidades, aprendizagem de idiomas estrangeiros, oportunidades profissionais e visão ampla e diferenciada, além de outros. Comparando esses resultados com outros estudos, esta pesquisa encontrou resultados similares aos de Lima et al. 
(2009), que constataram que os estudantes possuíam clara conviç̧ão de que o aprendizado do inglês proporcionaria o desenvolvimento de habilidades pessoais e profissionais.

Mazza (2011) identificou a exposição de estudantes em mobilidade a situações de preconceito e desigualdade. Nesta pesquisa, foram relatadas poucas situações nesse sentido, embora elas não tenham sido o foco da pesquisa. No caso da pesquisa de Guimarães (2013) sobre a mobilidade estudantil da UNESP Franca, os resultados indicam que a mobilidade tem aperfeiçoado o perfil do estudante que, em convívio com diferentes culturas e metodologias de ensino, pode adicionar ao seu currículo experiências que, com certeza, não vivenciaria cursando apenas a graduação. Esses resultados são sinalizados nesta pesquisa, pois os estudantes perceberam tais benefícios, embora seja prematuro afirmar que isso realmente aconteceu.

No final, as experiências sociais e interculturais dos estudantes são marcadas por laços de amizade, aventuras, o conhecimento, a fala negociada e os "perrengues". 


\section{CONSIDERAÇÕES FINAIS}

Nesta pesquisa, foram analisadas as experiências sociais e interculturais dos estudantes de administração da FAGEN/UFU no período de mobilidade estudantil internacional. Os resultados apontaram que as principais motivações identificadas durante as entrevistas foi o desejo de aprimorar a língua estrangeira e conhecer outros países, e as principais expectativas citadas foram: independência, viajar, conhecer o novo (pessoas e lugares), estudar em um nível de ensino mais elevado do que no Brasil e adquirir mais conhecimento.

Os desafios enfrentados pelos estudantes no período do programa de mobilidade foram a dificuldade com o idioma estrangeiro, a interação com os colegas de turma, a dificuldade em encontrar moradia, a saudade da família, as baixas temperaturas, as diferenças culturais e os desafios com trabalho e estágio. Ao colocar-se em contato com uma cultura diferente da realidade com a qual se está acostumado, é necessário que o estudante se adapte ao ritmo do país, ao estilo dos professores e dos novos colegas de turma. Permeia, também, a saudade do país de origem e da família, que ocasiona quase sempre muitas lágrimas. Porém, ao vivenciar uma experiência de mobilidade, o estudante permite-se sair da área de conforto em busca de novas experiências de vida.

Quanto aos benefícios da mobilidade estudantil percebidos pelos estudantes entrevistados, dentre aqueles que mais se destacaram, foi o crescimento pessoal e profissional, o autoconhecimento e a autoconfiança adquiridos, a ampliação do conhecimento, a transformação de uma visão mais ampla referente às coisas do mundo, a oportunidade de conhecer várias pessoas de diversas partes do planeta e o domínio do idioma estrangeiro. Nas entrevistas, foram relatadas algumas histórias que marcaram a experiência de viver no exterior. Algo que chamou atenção de alguns entrevistados foi a maneira como os indivíduos de outros países vivem, suas prioridades e a forma de encarar a vida.

A mobilidade estudantil internacional proporciona o encontro com um cenário culturalmente diverso em relação àquele de seu país de origem. 
Esse encontro entre culturas distintas no ambiente acadêmico torna-se positivo, visto que beneficia a diversidade de opiniões. Ademais, contribui para o desenvolvimento pessoal e a formação acadêmico-profissional do estudante, conforme citado pelos próprios entrevistados.

De modo geral, as experiências sociais e interculturais dos estudantes foram caracterizadas por laços de amizade, aventuras, conhecimento, fala negociada e "perrengues". Os laços de amizade criados nesse período foram mencionados e retratam o afeto e outros sentimentos que ajudaram nos momentos de desafio, como a saudade da família e as diferenças culturais. Os estudantes vivenciaram aventuras, aprenderam a "virar-se" sozinhos, percebendo-se como pessoas capazes de responder aos problemas surgidos no cotidiano. O conhecimento adquirido não só na escola, mas, também, nas situações vivenciadas no dia a dia, contribui para a formação pessoal e profissional do estudante. Os estudantes, em um dos desafios mais citados, negociaram suas falas nas tentativas de se comunicarem com o idioma estrangeiro. Os "perrengues", como citado por uma das entrevistadas, surgiram em diversos momentos de dificuldade.

As principais contribuições desta pesquisa residem em ampliar os estudos na área de mobilidade intercultural e na compreensão de culturas diversas, com isso, visando atingir o respeito mútuo de diferentes culturas. Além disso, ao analisar as experiências internacionais vivenciadas por estudantes, este estudo auxilia para a preparação de jovens estudantes relacionada a potenciais dificuldades e desafios na adaptação ao país estrangeiro. Finalmente, a pesquisa gerou resultados que podem contribuir para a criação de projetos e políticas institucionais e governamentais para que os estudantes alcancem, de forma satisfatória, os possíveis benefícios da mobilidade internacional.

Algumas das principais limitações metodológicas desta pesquisa foram: (a) a técnica de entrevista semiestruturada apresenta como desvantagem o fato de provocar insegurança ao entrevistado em relação ao seu anonimato e, por causa disso, muitas vezes, o entrevistado retém informações importantes; (b) a subjetividade do pesquisador na interpretação das entrevistas; e (c) o método utilizado não permite a generalização dos resultados para outros contextos. 
Em consonância com as limitações e lacunas da pesquisa, vislumbra-se uma agenda de pesquisas sobre o tema que considere: (1) pesquisar estudantes de outros cursos e outras universidades com o intuito de comparação dos resultados; (2) utilizar outros métodos de pesquisa e técnicas projetivas visando aprofundar-se no campo das emoções dos estudantes; (3) realizar estudos comparativos entre mobilidade estudantil nacional e internacional; (4) pesquisar a relação entre a mobilidade e a formação acadêmica do administrador; (5) pesquisar preconceitos e situações de constrangimento vivenciados pelos estudantes. 


\section{REFERÊNCIAS}

ANDRADE, J. V. Turismo: fundamentos e dimensões. São Paulo: Ática, 1998.

BARBLAN, A. Academic co-operation and mobility in Europe: how it was and how it will be. Higher Education in Europe, Brussels, v. 27, n. 1-2, 2002.

BARDIN, L. Análise de Conteúdo. Lisboa: Edições 70, 1979.

BECK, U. O que é Globalização? Equívocos do globalismo. Respostas à globalização. Tradução André Carone. São Paulo: Paz e Terra, 1999.

CABRAL, T. L. O.; SILVA, J. E. O.; SAITO, C. E. Realidade do Intercâmbio e da Mobilidade Acadêmica na Universidade Federal De Santa Catarina. In: COLÓQUIO INTERNACIONAL SOBRE GESTÃO UNIVERSITÁRIA NA AMÉRICA DO SUL, 11, 2011. Anais... Florianópolis, 2011.

CONTEL, F. B.; LIMA, M. C. Aspectos da internacionalização do ensino superior: origem e destino dos estudantes estrangeiros no mundo atual. Internext, v.2, n.2, p.167-193, 2007.

CRAIDE, A.; SILVA, F. B. A mobilidade e a gestão intercultural nas organizações. - Revista Pensamento Contemporâneo em Administração, v. 6, n. 1, p. 105-123, 2012.

FERNANDEZ, B. Identité nomade. Paris: Anthropos, 2002.

LICK, U. Desenho da pesquisa qualitativa. Porto Alegre: Artmed, 2009.

FREITAS, M. E. A mobilidade como novo capital simbólico nas organizações ou sejamos nômades? O\&S - Organizações e Sociedades, v. 16, n. 49, p. 247-264, 2009.

GUIMARÃES, O. M. A Globalização do conhecimento: Uma análise da mobilidade estudantil internacional dos estudantes da UNESP - Campus de Franca. Revista Camine - Caminhos da Educação, Franca, v. 5, n. 2, p. 147-157, 2013.

HILL, A; LYNCH, A.; DALLEY-TRIM, L. Positive educational responses to indigenous student mobility. International Journal of Educational Research, v. 54, p. 50-59, 2012.

IANNI, O. Teorias da globalização. 5.ed. Rio de Janeiro: Record, 1995.

LIMA, A. M.; NASCIMENTO, E. Mobilidade acadêmica na Universidade Federal de Santa Catarina: Relato de experiência. Ágora, Florianópolis, v. 22, n. 44, p. 125-135, 2012.

LIMA, M. C. et al. Motivações da Mobilidade Estudantil entre os Estudantes do Curso de Administração. In: ENCONTRO DE ENSINO E PESQUISA EM ADMINISTRAÇÃO E CONTABILIDADE - EnEPQ, 2, 2009. Anais... Curitiba: ANPAD, 2009.

LUNA, J. M. F.; SEHNEM, P. R. Erasmus e ciência sem fronteiras: considerações iniciais sobre mobilidade estudantil e política lingüística. RBPAE - Revista Brasileira de Política e Administração da Educação, São Paulo, v. 29, n. 3, p. 445-462, 2013. 
MAZZA, D. Mobilidade humana e educação: Os estudantes estrangeiros na UNICAMP. Cadernos CERU, v. 22, n. 1, p. 239-255, 2011.

MURPHY- LEJEUNE, E. The student experience of mobility, a contrasting score. Students, staff and academic mobility in higher education. Cambridge: Newcastle, 2008. SEBBEN, A. S. Intercâmbio Cultural: Para entender e se apaixonar. Porto Alegre: Artes e Ofícios, 2007.

SILVA, C. C. S. Mobilidade Corpórea de estudantes internacionais: as motivações dos estudantes internacionais acolhidos por instituições de educação superior localizadas em São Paulo e Belo Horizonte. 163f. 2013. Dissertação (Mestrado em Administração). ESPM - Escola Superior de Propaganda e Marketing, São Paulo, 2013.

SILVA, C. C. S.; LIMA, M. C. A Relevância das Novas Mobilidades e a Pertinência dos Métodos Móveis. In: ANPAD, 37, 2013. Anais... Rio de Janeiro: ANPAD, 2013.

SILVA, C. C. S.; LIMA, M. C.; RIEGEL, V. Os Fatores de Motivação na Definição de Estudantes Estrangeiros em Mobilidade Acadêmica Internacional no Brasil, Revista GUAL, v. 6, n. 3, p. 232-251, 2013.

SPEARS, E. O valor de um intercâmbio: mobilidade estudantil brasileira, bilateralismo \& internacionalização da educação. Revista Eletrônica de Educação, v.8, n.1, p.151-163, 2014.

STALLIVIERI, L. O processo de internacionalização nas instituições de ensino superior. Educação Brasileira, v. 24, n. 48-49, p. 35-57, 2003.

TOMAZZONI, E. L.; OLIVEIRA, C. C. Turismo de Intercâmbio: Perfis dos intercambistas, motivações e contribuições da experiência internacional. Revista Turismo Visão e Ação, v. 15, n. 3, p. 388-408, 2013. 


\title{
DADOS DOS AUTORES
}

CINTIA RODRIGUES DE OLIVEIRA MEDEIROS`cintia@ufu.br Doutora em Administração - Estudos Organizacionais pela FGV/EAESP Instituição de vinculação: Universidade Federal de Uberlândia Uberlândia/MG - Brasil

Áreas de interesse em pesquisa: Estudos Organizacionais.

* Av. João Naves de Avila, 2121 Santa Monica Uberlândia/MG 38408-100

\author{
ANTONIA DARLIANE DA SILVA ANDRADE darlianesud@hotmail.com \\ Bacharel em Administração pela UFU \\ Instituição de vinculação: Universidade Federal de Uberlândia \\ Uberlândia/MG - Brasil \\ Áreas de interesse em pesquisa: mobilidade, cultura organizacional e formação do \\ administrador.
}

\section{JANDUHY CAMILO PASSOS camilo@ufu.br}

Doutor em Administração - Estudos Organizacionais pela FGV/EAESP

Instituição de vinculação: Universidade Federal de Uberlândia

Uberlândia/MG - Brasil

Áreas de interesse em pesquisa: Estudos Organizacionais, Comportamento

Organizacional e Psicologia do Trabalho. 